\title{
COMUNICAÇÃO EM ONCOLOGIA E BIOÉTICA
}

A comunicação muda uma situação. Para melhor ou para pior. Indispensável para a sustentação ética do vínculo médicopaciente num ciclo de atendimento, quando sua significação revela a crueldade de uma doença de mau prognóstico, pode provocar a conscientização que surgirão mudanças transitórias ou definitivas na qualidade de vida, incluindo ideias de aceleração em direção ao final de vida(1-3).

A má notícia que pode afetar negativa e seriamente a visão do futuro fica pior se mal comunicada. Há estratégias de comunicação na área da saúde que objetivam evitar tanto a carência quanto o exagero na emissão/recepção. Uma sequência estruturada objetiva considerar a informação reunida desde o paciente, a transmissão dos dados médicos, o suporte ao paciente e o estabelecimento do comprometimento do paciente com o planejamento das condutas. Em oncologia, o protocolo SPIKES exemplifica a noção de utilidade de passos sequentes fundamentados em preparação (tempo é fundamental), percepção (do já sabido pelo paciente), informação (se desejada pelo paciente), conhecimento (produzir esclarecimento), atenção à emoção (valor da empatia) e cooperação (caminhar junto ante as necessidades) $)^{4}$.

A doença oncológica, como sistema biológico que envolve tumor primário, metástases, traços genéticos e hábitos de vida, expressa a alta dimensão do poder da palavra da ciência sobre a rotina do paciente ${ }^{5}$. Seus aspectos psicossociais sofrem influência do conceito arraigado de uma doença sem volta, apesar do panorama auspicioso proporcionado pelos sucessivos progressos da especialidade/disciplina em conhecimentos e capacitações.

Médicos e pacientes compartilham palavras de incerteza em oncologia. É preciso que elas contribuam para decisões façam sentido numa situação plena de dilemas que, ao mesmo tempo, sinaliza as limitações técnico-científicas da medicina - que fazem conviver benefícios nem sempre suficientes e malefícios muitas vezes excessivos-, e alerta para decorrente possibilidade de redirecionamento dos cuidados terapêuticos para paliativos ${ }^{6}$.

A expressão do impacto da comunicação sobre o paciente é sensível ao quanto às atitudes empregadas pelo médico - e equipe multiprofissional- compõem-se às boas práticas para esclarecer ao leigo a medicina longe da perfeição. Porque é da inquietude profissional que o continuum de aperfeiçoamento dos métodos úteis e eficazes seja visto, comumente, como aquém do grau da segurança desejada, a promoção de esclarecimentos não pode dispensar a aclimatação humana do ser médico-ser paciente e a harmonização às convenções ético-legais determinadas pela sociedade.

O oncologista alinha a experiência própria à da coletivizada na literatura e utiliza passados clínicos análogos para prenunciar o futuro que pode vir a requerer desafios de aceitação de realidades desconfortáveis, o compromisso com a sobrevivência e a exigência de dignidade na morte.

Fortes emoções surgem em meio à autenticidade da verdade, a caridade da suavização possível e a compaixão de silêncios intervalados pela intenção do médico não ser indiferente, nem à doença nem ao doente, uma unidade complexa de conflitos. Ansiedade, raiva, culpa, receio de mudança nos relacionamentos, afastamento de funções na família e no trabalho, perda da independência e preocupações financeiras combinam-se, provocam hesitações e acentuam óbices à capacidade de compreensão do paciente.

A qualidade da comunicação, especialmente de más notícias, associa-se à grandeza da sintonia provocada. 0 desejo bilateral por ajustes de entendimento faz com que o dito possa ser redito e o que faltou possa ser acrescentado. Desta forma, o continuum da informação, que é habitual para o oncologista e incomum para o paciente, surpreendido pelo diagnóstico e desdobramentos, resulta melhor reorganizado.

A beira do leito ensina o quanto não se deve pretender predeterminações rígidas sobre atitudes em comunicação envolvendo o portador de moléstia oncológica, há estilos na emissão, gradações de empatia e de repulsão na recepção não são facilmente previsíveis ${ }^{7}$.

Os médicos experientes colecionam sucessos e insucessos de esclarecimentos desejados. Eles compõem uma curva de aprendizado em serviço que ascende, sustentada por análises sistematizadas e periódicas dos fatos reais da comunicação e pela compreensão de peculiaridades sociais e culturais.

Primo e Garrafa ${ }^{8}$ buscaram dados da realidade brasileira. Eles aplicaram nove questões a 120 mulheres distribuídas em ampla faixa etária (21 a 78 anos) com média jovem (40,3 anos), pretendendo avaliar a qualidade da comunicação sobre diagnóstico, tratamento e prognóstico de câncer genital ou de mama. Por meio de uma concepção descritivo-analítica de corte transversal, analisaram pacientes com doença maligna que estavam na fase de atendimento em ambulatório especializado de oncologia. Os autores mesclaram casos em fases avançadas $(66,6 \%)$ e iniciais $(33,3 \%)$ da doença oncológica.

As três questões sobre diagnóstico envolveram a primeira informação, subentendendo a pluralidade de sua consecução em múltiplos locais do encaminhamento do caso, a uniformidade da reinformação num ambiente especializado e a perspectiva de contraposições de esclarecimento.

O quarteto de questões sobre tratamento pretendeu conhecer o desejo de envolvimento com as opções pelo paciente, a sua compreensão das diferenças, a aptidão e o clima para a participação ativa na seleção. 
As duas questões sobre prognóstico reforçaram o aspecto de adesão ao tratamento e aprofundamento do conhecimento sobre possibilidades evolutivas.

Três questões resultaram com evidente superposição de respostas, todas elas referentes ao enunciado quer saber $83,3 \%$ e $83,4 \%$ disseram sim, respectivamente, sobre opções de tratamento e sobre tudo da doença- e sabe - 63,4\% afirmaram estar cientes da progressão natural.

Portanto, a pesquisa destacou que as mulheres envolvidas almejavam sentir-se informadas sobre o desenvolvimento da moléstia.

Por outro lado, Primo e Garrafa evidenciaram uma heterogeneidade de respostas sobre comportamento dos médicos, assimilação pela paciente e sensação de liberdade/competência para participar ativamente em tomada de decisão.

Esses dados robustecem que, por mais que se possa valer da intuição na comunicação em saúde, devem ser desenvolvidos programas de treinamento com a finalidade da obtenção do maior grau de lucidez sobre essas variáveis, aplicável a um país continental e pluriétnico.

A Bioética reforça o conceito que as boas práticas em assuntos de saúde exigem eficiência na comunicação. O seu envolvimento interdisciplinar provê subsídios para que individualizações nas composições resultem mais compreensivas sobre benefícios e malefícios. Ocorrendo mais entendimento racional, haverá menos preenchimento de lacunas por inaplicável analogia e indesejável imaginação. Facilita-se, assim, a deliberação perante a complexidade das decisões em oncologia.

Deste modo, a Bioética valoriza o aprimoramento das derivações de diálogo para a melhor adaptação às partes envolvidas. A Bioética dá forte sustentação à condução do caso de acordo com a maior ou a menor aceitação do exercício da autonomia oferecido ao paciente e com eventuais controvérsias na maneira de ver a tomada de decisão como negligência ou imprudência.

Primo e Garrafa, por sua análise do efeito da palavra sobre o que já aconteceu e sobre o que poderá acontecer em um grupo de pacientes com doença oncológica passível de impacção sobre a identidade feminina, trazem dados proveitosos para a construção da excelência em comunicação perante doença oncológica. É contribuição bem-vinda à harmonia do trinômio Ciência- Educação-Ser humano.

Max Grinberg

Diretor da Unidade Clínica de Valvopatias do Instituto do Coração do Hospital das Clínicas da Faculdade de Medicina da Universidade de São Paulo - HCFMUSP

Referências

1.Buckman R- Communications and emotions. BMJ. 2002 September 28; 325(7366): 672.

2. Maguire P, Pitceathly C -Managing the difficult consultation. Clin Med. 2003 Nov-Dec; 3(6):532-7.

3. Fallowfield L, Jenkins V- Communicating sad, bad, and difficult news in medicine.Lancet. 2004 Jan 24;363(9405):312-9.

4.Baile WF, Buckman R, Lenzi R, Glober G, Beale EA, Kuldera AP - SPIKESA Six-Step Protocol for Delivering Bad News: Application to the Patient with Cancer. The Oncologist 2000;5:302-311

5.Baile WF, Aaron J - Patient-physician communication in oncology: past, present, and future. Curr Opin Oncol. 2005 Jul;17(4):331-5.

6.Fine E, Reid MC, Shengelia R, Adelman RD- Directly observed patientphysician discussions in palliative and end-of-life care: a systematic review of the literature. J. Palliat Med. 2010-May;13(5):595-603.

7.Grinberg M, Cohen C - Falando com o coração: auscultando a Bioética. Revista da Sociedade de Cardiologia do Estado de São Paulo, v. 12, n. 6, p. 805-820, 2002.

8.Primo WQSP, Garrafa V- Análise ética da revelação do diagnóstico e tratamento em pacientes com câncer genital ou mamário. Rev Assoc Med Bras. 2010; 56(4): 397-402. 